\title{
Articles
}

\section{Psychometric Properties and Validity of Dyadic Coping Inventory-Urdu Version for Use in Pakistan}

\author{
Sultan Shujja*a, Adnan Adila, Ashley K. Randall ${ }^{b}$, Guy Bodenmannc ${ }^{\text {, Farah Malik }}{ }^{d}$
}

[a] Department of Psychology, University of Sargodha, Sargodha, Pakistan. [b] Faculty of Counseling and Counseling Psychology, Arizona State University, Tempe, AZ, USA. [c] Department of Psychology, University of Zurich, Zurich, Switzerland. [d] Institute of Applied Psychology, University of the Punjab, Lahore, Pakistan.

\begin{abstract}
For married individuals living in Pakistan, stress within their relationship has emerged as a major source of marital conflicts and even relationship dissolution. However, research based on the systemic transactional model of dyadic coping (DC) suggests partners' use of coping strategies may help in buffering these devastating effects of stress. The original German version of the Dyadic Coping Inventory $(\mathrm{DCl})$ is a widely used self-report measure that has been translated in various languages, however, has not been validated for use with individuals living in Pakistan who speak Urdu. The purpose of the present study was to translate and validate the DCI into Urdu for use with married individuals living in Pakistan. Data were collected from 538 Pakistani married adults. Findings supported the original factor structure of the German and English version of the DCl. As such, results supported the 33-items DCl-Urdu as a valid and reliable measure to assess DC behaviors in Pakistani married individuals. Further, convergent and discriminant validity and measurement invariance (MI) across gender for the $\mathrm{DCl}-U$ rdu were consistent with that of $\mathrm{DCl}$-English. A validated measure of the $\mathrm{DCl}$ in Urdu provides new directions for researchers and clinicians working with couples in Pakistan.
\end{abstract}

Keywords: dyadic coping inventory, dyadic coping, stress, marital relationship, Pakistan

Interpersona, 2020, Vol. 14(2), 183-199, https://doi.org/10.5964/ijpr.v14i2.4069

Received: 2020-07-18. Accepted: 2020-11-04. Published (VoR): 2020-12-22.

*Corresponding author at: Department of Psychology, University of Sargodha, Sub-Campus, Bhakkar, Gymnasium Rd, Bhakkar, Punjab, Pakistan. Email: sultanshujja@gmail.com

This is an open access article distributed under the terms of the Creative Commons Attribution 4.0 International License, CC BY 4.0 (https://creativecommons.org/licenses/by/4.0/), which permits unrestricted use, distribution, and reproduction in any medium, provided the original work is properly cited.

The experience of stress is, unfortunately, a world-wide phenomenon (Falconier et al., 2016; Hilpert et al., 2016; Mujtaba, Lara, King, Johnson, \& Mahanna, 2010). In Pakistan, approximately 50 million adults are suffering from various mental illnesses including anxiety disorders and depression as a result of stress (Ali \& Gul, 2018; Gallup Pakistan, 2019; Sarfraz, 2017; World Health Organization, 2016). Since 1990, researchers interested in romantic relationships have started investigating the systemic effects of stress; in particular how individual stress may influence partners' behavior, also known as dyadic stress (Falconier et al., 2016; Randall \& Bodenmann, 2009).

Research on dyadic stress and coping have spanned over three decades and several models such as Coyne and Smith's (1991) relationship focused coping model, DeLongis and O'Brien's (1990) empathic coping model, Revenson's (1994) congruence coping model, and Bodenmann's (1997) systemic-transactional model, have been developed. While all of the models examining dyadic stress focus on the ways in which romantic couples 
face and cope with stress, the systemic transactional model focuses explicitly on partners' stress communication and dyadic coping behaviors, which can be measured with the self-report Dyadic Coping Inventory (DCl; Bodenmann, 2008).

\section{Systemic Transactional Model}

A key premise related to the systemic transactional model (STM; Bodenmann, 1995, 2005, 2007) is that the experience of one family member's stress affects the other family members (i.e., it is systemic). Specifically, one partner's experience of stress affects their partner by stress spillover and/or stress crossover. Stress spillover refers to the transmission of stress from one domain of life to another (e.g., external stress originating outside the relationship becomes internal stress or stress within the relationship), whereas stress crossover refers to the dyadic process in which one individuals' feelings of stress crosses over to the partner, causing the partner to feel stressed (Bakker et al., 2009). As an example, if a married woman in Pakistan is unable to conceive a child within the first two or three years of marriage, her in-laws may blame her as infertile. This may cause undue stress on the woman, which ultimately affects their partner as well (Qadir et al., 2011).

\section{Coping With Stress}

According to the STM (Bodenmann, 2005), dyadic coping (DC) is defined as the process by which partners help each other when one or both are experiencing stress. The process of DC starts when one partner communicates a stressful experience to the other partner either verbally (e.g., discussing issues related to in-laws aiming at jointly searching for a solution) or nonverbally (e.g., shutting down and avoiding conversation). The non-stressed partner interprets theses stress signals and can either choose to respond positively or negatively to their partner. Positive DC includes problem-focused DC (e.g., giving advice to the partner to bring the grievances to the in-laws), emotion-focused DC (e.g., providing emotional support), or delegated DC (e.g., taking responsibility of childcare while the partner relaxes). Partners can also engage in negative DC by providing ambivalent support (Bodenmann, 1997; 2005). For example, men hold their partners responsible for conflict with in-laws in Pakistan. Furthermore, common or joint DC is displayed when stressors affect both partners simultaneously, such as child rearing responsibilities and issues in Pakistan (Arshad \& Iqbal, 2016). A common way for researchers and clinicians working with couples to assess dyadic coping behaviors is to administer the self-report DCl (Bodenmann, 2008).

\section{Measuring DC}

The DCl (Bodenmann, 2008) is a self-report instrument designed to assess partners' stress communication and dyadic coping behaviors. Originally developed in German, the $\mathrm{DCl}$ has been translated and validated in different languages. So far, validation studies were published in Chinese (Xu, Hilpert, Randall, Li, \& Bodenmann, 2016), English (Randall, Hilpert, Jimenez-Arista, Walsh, \& Bodenmann, 2016), French (Ledermann, Bodenmann, Rudaz, \& Bradbury, 2010), Italian (Ledermann et al., 2010), Japanese (Yokotani \& Kurosawa, 2015), Persian (Fallahchai, Fallahi, Chahartangi, \& Bodenmann, 2019), Polish (Wendołowska, Czyżowska, \& Bodenmann, 2020), Portuguese (Vedes, Nussbeck, Bodenmann, Lind, \& Ferreira, 2013), Romanian (Rusu, Hilpert, Turliuc, \& Bodenmann, 2016), and Spanish (Falconier et al., 2013). All the validation studies of $\mathrm{DCl}$ mentioned above support the factor structure originally reported in validation study of DCl-German (Bodenmann, 2008), with a few caveats for culturally sensitive items. 


\section{Role of Stress and Coping in Pakistan}

Pakistan provides a unique canvas for studying dyadic stress and coping processes due to its unique cultural characteristics associated with marital relationships. In particular, Pakistan endorses arranged marriages (Khalil, Naeem, Yousafzai, \& Gul, 2014; Zafar \& Kausar, 2014), endogamous marriages (married couple must be from the same caste; Saleem, Chaudhry, \& Riaz, 2015), and exchange marriages, where a daughter from one family gets married with the son another family (usually blood relatives) and the other family's daughter gets married with the son from the first family in return (Zaman, 2011a). Because of these practices, partners may experience unfamiliarity with their partners' attitude, behaviors, and habits, which may result in varied level of stress (Arif \& Fatima, 2015; Arshad \& lqbal, 2016; Fatima \& Ajmal, 2012; Mir, Wani, \& Sankar, 2016; Niaz, 2004; Zaman \& Ali, 2014). Despite the growing research evidence related to dyadic stress and coping for couples across the world (for a review see Falconier et al., 2016), principles associated with stress communication and dyadic coping are still understudied in Pakistan due to a lack of availability of a standardized self-report measure of dyadic coping. As such, the goal of the present study is to fill this important gap in the literature.

\section{The Present Study}

Partners' dyadic coping is found to be positively associated with lower stress and higher well-being (Falconier et al., 2015); however, understanding how dyadic coping may work for married individuals in Pakistan has been largely ignored due to the unavailability of a standardized measure. According to Pakistan Economic Survey (UNESCO, 2018), most of the Pakistani adults (99.7\%) speak and understand Urdu and perceive themselves at ease in reading and understanding the contents presented in this language. Thus, the aim of the present study was to develop and validate the DCl-Urdu for use in Pakistan. In addition to the development that included translation and back translation procedures (Acquadro, Conway, Giroudet, \& Mear, 2012), we also examined convergent and discriminant validity. Lastly, measurement invariance (MI) was conducted to examine the equivalence across gender on five-factor structure of $\mathrm{DCl}$ as reported by previous validation studies of $\mathrm{DC}$ (e.g., Randall et al., 2016).

\section{Method}

\section{Recruitment and Participants}

Participants were recruited from three cities (Bhakkar, Lahore, Sargodha) in Pakistan using a snowball sampling technique. Participants currently living in Pakistan and in their first marriage for at least 2 years were eligible to participate. A total of 560 married adults ( $n=278$ men and $n=282$ women) were recruited for the study. During initial screening, twelve women withdrew because they did not have their in-laws permission to participate. Seven men were excluded because they did not meet aforementioned criterion (i.e., they were in their second marriage), and three men refused to proceed without giving any reason.

The final sample comprised of 538 adults $(n=268$ men and $n=270$ women), ranging in age from 22-72 years $(M=37.19, S D=10.3$ years $)$ for men and 18-69 years $(M=32.15, S D=8.56$ years $)$ for women. Approximately $21.6 \%$ men and $23.8 \%$ women completed high school education, $74.2 \%$ men completed formal collage/university education compared to $68.9 \%$ women and $4.1 \%$ men attained MPhil/PhD degree compared to $3 \%$ women. Majority of the respondents $(68.3 \%$ men and $58.1 \%$ women) belonged to middle class socioeco- 
nomic status with family income per month $(M=92,340$ Pakistan rupees [PKR], $S D=23,981 \mathrm{PKR})$. Men's average reported relationship length was 10.35 years, $S D=8.78$, range 2-39 years; women reported an average relationship length was 9.98 years, $S D=8.78$, range $2-44$ years.

\section{Measures}

\section{Dyadic Coping Inventory (DCl)}

The $\mathrm{DCl}$ is a 37-item self-report measure designed to assess stress communication and partners' dyadic coping behaviors (Bodenmann, 2008). Participants report on perceptions of their own (self) and their partner's (partner) DC behaviors. The DCl also assesses common DC behavior when both partners are stressed (common DC). The respondents rate each item on a 5-point Likert type response format that ranges from very rare (1) to very often (5). The details of the DCl subscales are presented in Table 1.

Table 1

Description of $D C I$ Subscales

\begin{tabular}{|c|c|c|}
\hline Variable & Item & Sample item \\
\hline \multicolumn{3}{|l|}{ Self } \\
\hline Stress Communication & 4 & I show my partner through my behavior when I am not doing well or when I have problems \\
\hline Emotion Focused Supportive DC & 3 & I show empathy and understanding to my partner \\
\hline Problem Focused Supportive DC & 2 & $\begin{array}{l}\text { I try to analyze the situation together with my partner in an objective manner and help } \\
\text { him/her to understand and change the problem }\end{array}$ \\
\hline Delegated DC & 2 & I take on things that my partner would normally do in order to help him/her out \\
\hline Negative DC & 4 & I blame my partner for not coping well enough with stress \\
\hline \multicolumn{3}{|l|}{ Partner } \\
\hline Stress Communication & 4 & $\begin{array}{l}\text { My partner shows me through his/her behavior that he/she is not doing well or when } \\
\text { he/she has problems }\end{array}$ \\
\hline Emotion Focused Supportive DC & 3 & My partner shows empathy and understanding to me \\
\hline Problem Focused Supportive DC & 2 & My partner helps me analyze the situation so that I can better face the problem \\
\hline Delegated DC & 2 & My partner takes on things that I normally do in order to help me out \\
\hline Negative DC & 4 & My partner provides support, but does so unwillingly and unmotivated \\
\hline Emotion Focused Common DC & 2 & We are affectionate to each other, make love and try that way to cope with stress \\
\hline Problem Focused Common DC & 3 & We try to cope with the problem together and search for ascertained solutions \\
\hline Evaluation of DC & 2 & $\begin{array}{l}\text { I am satisfied with the support I receive from my partner and the way we deal with stress } \\
\text { together }\end{array}$ \\
\hline
\end{tabular}

Note. DC = dyadic coping.

Reliability estimates for the total DC $\left(\alpha_{\text {men }}=.81\right.$ and $\left.\alpha_{\text {women }}=.90\right)$ and subscales were within acceptable ranges $\left(\alpha_{\text {women }}=.60-.72, \alpha_{\text {men }}=.60-.82\right)$, with the exception of stress communication by self $\left(\alpha_{\text {women }}=.41\right)$, problem-focused supportive DC by self $\left(\alpha_{\text {men }}=.50\right.$ and $\left.\alpha_{\text {women }}=.43\right)$, delegated DC by self $\left(\alpha_{\text {women }}=.53\right.$ ). Reasonably high alpha coefficients were estimated for the composite DC by self $\left(\alpha_{\text {men }}=.77\right.$ and $\left.\alpha_{\text {women }}=.72\right)$ and DC by partner $\left(\alpha_{\text {men }}=.77\right.$ and $\alpha_{\text {women }}=.73$; see Table 2$)$.

\section{Translation of the DCI Into Urdu}

To translate the English version of the DCl (Randall et al., 2016) into Urdu, two experts were recruited who met the criteria for translation recommended by MAPI Research Trust (Acquadro et al., 2012). The translators had at least five years of experience in scale translation, held a PhD in Psychology, and were fluent in both Urdu 
and English. Using the procedures outlined by MAPI guidelines (Acquadro et al., 2012), the two translators first translated the $\mathrm{DCl}$ from English into Urdu. Following this, three experts examined the initial translation of the DCl items from English to Urdu. Next, three experts in Pakistan who held a PhD in Psychology and over 15 years of translation experience, examined linguistic expression, cultural connotations, and grammatical structure of Urdu statements. On the recommendations of these subject experts, a best-consolidated translation draft was prepared. In order to substantiate the semantic equivalence between DCl-Urdu and English version of the DCl (Randall et a., 2016), DCl-Urdu was translated into English.

Following the back-translation procedure, two bilingual experts who had MPhil English degree and five years of teaching experience in Department of English at the University of Sargodha, back-translated the DCl-Urdu version to English. In order to assess the compatibility of the two back translations of the DCl- Urdu with DCI (English; Randall et al., 2016), two subject experts who held a PhD in English Language \& Literature and 15 years teaching experience in Department of English at the University of Sargodha, examined the back translations. Based on their review, the finalized draft of the $\mathrm{DCl}$ was ready for empirical evaluation.

\section{Cultural Adaptation of the DCI-Urdu}

Prior to validating the $\mathrm{DCl}-U r d u$, the translated items were reviewed by experts in Pakistan to determine their appropriateness. They made qualitative judgment about the cultural appropriateness of the $\mathrm{DCl}$ in order to ensure ecological validity. Upon review, all the items of the $\mathrm{DCl}$ appeared to be culturally unbiased except item 34 "We help each other relax with such things like massage, taking a bath together, or listening to music together" that was found to have culturally inappropriate connotations. Given the religious, social, and cultural norms that restrict sharing of private matters openly (Ali et al., 2011), Pakistani adults are unlikely to openly discuss or even talk about activities like massage or taking a bath together. With the consent of original author of the DCI (Bodenmann, 2008) and relationship researchers in Pakistan, we revised item 34 to read "We help each other relax by doing such activities (e.g., shopping, listening to music, or visiting the hill station)"

\section{Relationship Assessment Scale (RAS)}

RAS was developed by Hendrick et al. (1998). The current study used the Urdu version of the RAS (Shahid, 2014) that is a 7-item one-dimensional self-report measure designed to assess the extent to which an individual is satisfied with their relationship. For the purpose of this study, the RAS was administered as a measure of convergent validity. Participants are asked to rate each item on a 5-point Likert type response format indicating low level of satisfaction (1) to high level of satisfaction (5) with relationship with partner. The sample items of RAS are "How well does your partner meet your needs?" and "How much do you love your partner?". In the current study, reliability estimates for the RAS was found to be acceptable for the men $(\alpha=.91)$ and women ( $\alpha$ $=.86$ ).

\section{The Brief COPE}

The Brief COPE was developed by Carver (1997). The current study used its Urdu version (Akhtar, 2005) that is a 28-item self-report measure designed to assess individual coping behaviors. For the purpose of this study, the Brief COPE was administered as a measure of discriminant validity. It contained 28 items and 14 factors i.e., self-distraction, active coping, denial, substance use, use of emotional support, use of instrumental support, behavioral disengagement, venting, positive reframing, planning, humor, acceptance, religion and self-blame). Respondents rated each item on a 4-point Likert type response format ranging from I have not been doing it at all (1) to I have been doing this a lot (4). For the purpose of our study, two items from use 
of emotional support subscale "I've been getting emotional support from others" and "I've been getting comfort and understanding from someone" and two from the humor subscale "I've been making jokes about it" and "I've been making fun of the situation" were used because these scales showed highest alpha reliabilities amongst the subscales of the Brief COPE (Urdu) for the Pakistani population. The alpha reliabilities for the Brief COPE subscales were found to be acceptable for men ( $\alpha_{\text {use of emotional support }}=.68 ; \alpha_{\text {humor }}=.81$ ) and women $\left(\alpha_{\text {use of }}\right.$ emotional support $=.70 ; \alpha_{\text {humor }}=.79$ ).

\section{Results}

Reliabilities, means, standard deviations, and independent sample $t$-test were computed to examine mean score difference between men and women. In order to assess the issue of acquiescence i.e., a tendency to agree rather than disagree with the proposition in general (Lentz, 1938) as a potential source of response bias, percentage of extreme response options (never/rarely often vs very often) were computed. Results demonstrated that respondents rated the items on never/very rarely (19.78\%) compared to the very often (28.22\%), which suggests minimal differences between the two propositions ruling out the possibility of the acquiescence.

Findings of independent sample $t$-test reported in Table 2 showed that, women reported significantly higher stress communication compared to men, $t(536)=2.80, p<.05$. Additionally, women reported higher delegated $\mathrm{DC}$ by self, $t(536)=2.45, p<.05$, whereas men reported higher delegated DC by partners, $t(536)=2.81, p$ $<.05$. Overall, women reported a higher use of overall DC by self, $t(536)=2.69, p<.05$, compared to men.

Table 2

Gender-Wise Mean Differences on Total DCl and Its Subscales Along With Alpha Coefficients

\begin{tabular}{lccccc}
\hline Source & $\boldsymbol{M}(\boldsymbol{S D}) \mathbf{M e n}$ & $\boldsymbol{M}(\boldsymbol{S D})$ Women & $\boldsymbol{t}(\mathbf{5 3 6})$ & $\boldsymbol{\alpha}_{\text {men }}$ & $\boldsymbol{\alpha}_{\text {women }}$ \\
\hline Stress Communication (Self) & $3.48(0.71)$ & $3.64(0.65)$ & $2.80^{*}$ & .60 & .41 \\
Emotion Focused Supportive DC (Self) & $3.86(0.82)$ & $3.97(0.80)$ & 1.45 & .71 & .67 \\
Problem Focused Supportive DC (Self) & $3.61(0.78)$ & $3.63(0.79)$ & 0.45 & .50 & .43 \\
Delegated DC (Self) & $3.28(0.93)$ & $3.47(0.87)$ & $2.45^{*}$ & .63 & .53 \\
Negative DC (Self) & $3.27(1.04)$ & $3.42(1.32)$ & 1.30 & .86 & .86 \\
Stress Communication (Partner) & $3.57(0.69)$ & $3.42(0.72)$ & $2.48^{*}$ & .64 & .60 \\
Emotion Focused Supportive DC (Partner) & $3.84(0.86)$ & $3.76(0.85)$ & 1.13 & .70 & .60 \\
Problem Focused Supportive DC (Partner) & $3.65(0.89)$ & $3.61(0.91)$ & 0.58 & .60 & .62 \\
Delegated DC (Partner) & $3.38(0.99)$ & $3.14(1.01)$ & $2.81^{*}$ & .60 & .63 \\
Negative DC (Partner) & $3.11(1.19)$ & $3.25(1.17)$ & 1.38 & .80 & .79 \\
Emotion Focused Common DC & $3.61(1.02)$ & $3.65(1.03)$ & 0.38 & .70 & .60 \\
Problem Focused Common DC & $3.73(0.86)$ & $3.77(0.86)$ & 0.55 & .80 & .77 \\
Evaluation of DC & $4.01(0.98)$ & $4.06(0.97)$ & 0.083 & .82 & .77 \\
Total DC Self & $3.49(0.59)$ & $3.62(0.55)$ & $2.69^{*}$ & .77 & .72 \\
Total DC Partner & $3.49(0.58)$ & $3.43(0.58)$ & 1.15 & .77 & .73 \\
Total DC & $3.41(0.53)$ & $3.42(0.50)$ & 0.81 & .90 & .83 \\
\hline Note DC = dyadic coping & & & & &
\end{tabular}

Note. DC = dyadic coping.

${ }^{*} p<.05$.

The inter-correlations among the DCl-Urdu and its subscales for men and women are represented in Table 3. Findings revealed that correlation coefficients between overall DC with DC by self $\left(r_{\text {men }}=.92, p<.001 ; r_{\text {women }}\right.$ 
$=.87, p<.001)$ and DC by partner $\left(r_{\text {men }}=.92, p<.001 ; r_{\text {women }}=.91, p<.001\right)$ shared common variance across gender. The correlation coefficients for all the subscales of $\mathrm{DCl}$-Urdu were found to be significant at .01 and .001 alpha level except negative DC by self and partner with stress communication by self, emotion-focused supportive DC by self, problem-focused supportive DC by self, and delegated DC by self for women.

Table 3

Gender-Wise Intercorrelations Among DCl and Its Sub-Scales

\begin{tabular}{|c|c|c|c|c|c|c|c|c|c|c|c|c|c|c|c|c|}
\hline Variable & 1 & 2 & 3 & 4 & 5 & 6 & 7 & 8 & 9 & 10 & 11 & 12 & 13 & 14 & 15 & 16 \\
\hline 1. $S C(S)$ & - & $.50 * *$ & $.41^{\star *}$ & $.32^{* *}$ & .07 & $.42^{\star *}$ & $.48^{* *}$ & $.40^{* *}$ & $.33^{\star *}$ & $.12^{*}$ & $.43^{\star *}$ & $.44^{\star *}$ & $.42^{* *}$ & $.64^{\star *}$ & $.50 * *$ & $.62^{\star \star}$ \\
\hline 2. EFSDC (S) & $.41^{\star *}$ & - & $.59^{* *}$ & $.33^{\star *}$ & $.16^{*}$ & $.56^{\star *}$ & $.56^{\star *}$ & $.53^{\star *}$ & $.33^{* *}$ & $.12^{*}$ & $.51^{\star *}$ & $.62^{* *}$ & $.59^{* *}$ & $.70^{* *}$ & $.58^{* *}$ & $.71^{\star *}$ \\
\hline 3. PFSDC (S) & $.28^{\star *}$ & $.54^{\star *}$ & - & $.36^{\star *}$ & .06 & $.43^{\star *}$ & $.45^{\star *}$ & $.38^{* *}$ & $.26^{\star *}$ & .04 & $.44^{\star *}$ & $.53^{\star *}$ & $.46^{\star *}$ & $.59^{* *}$ & $.43^{* *}$ & $.57^{\star \star}$ \\
\hline 4. DDC (S) & $.26^{\star *}$ & $.33^{\star *}$ & $.39^{* *}$ & - & .03 & $.28^{\star *}$ & $.31^{\star *}$ & $.24^{* *}$ & $.30^{* *}$ & -.02 & $.30 * *$ & $.29^{\star *}$ & $.23^{\star *}$ & $.49^{\star *}$ & $.28^{* *}$ & $.42^{\star \star}$ \\
\hline 5. NDC (S) & .03 & .08 & -.04 & .03 & - & .09 & .09 & .06 & -.01 & $.79^{\star *}$ & 06 & $.13^{*}$ & $.19^{* *}$ & $.66^{\star *}$ & $.49^{\star *}$ & $.66^{* \star}$ \\
\hline 6. $S C(P)$ & $.41^{* *}$ & $.42^{\star *}$ & $.39^{* *}$ & $.33^{* *}$ & -.04 & - & $.54^{\star *}$ & $.46^{* *}$ & $.39^{* *}$ & .03 & $.45^{\star *}$ & $.48^{* *}$ & $.44^{* *}$ & $.47^{* *}$ & $.67^{* *}$ & $.63^{* *}$ \\
\hline 7. EFSDC (P) & $.39 * *$ & $.39^{\star *}$ & $.30^{* *}$ & $.17^{*}$ & .07 & $.44^{\star *}$ & - & $.57^{\star *}$ & $.41^{* *}$ & .06 & $.49^{\star *}$ & $.54^{\star *}$ & $.56^{\star *}$ & $.51^{\star *}$ & $71^{* *}$ & $68^{* *}$ \\
\hline 8. PFSDC (P) & $.35^{\star *}$ & $.39^{* *}$ & $.39^{* *}$ & $.18^{*}$ & .05 & $.34^{* *}$ & $.50^{* *}$ & - & $.51^{* *}$ & .01 & $.44^{\star *}$ & $.54^{\star *}$ & $.56^{\star *}$ & $.43^{\star *}$ & $64^{* *}$ & $60^{* *}$ \\
\hline 9. DDC (P) & $.34^{* *}$ & $.15^{\star}$ & .11 & $.12^{*}$ & -.06 & $.30^{\star *}$ & $.27^{\star *}$ & $.40^{* *}$ & - & .005 & $.34^{* *}$ & $.30^{* *}$ & $.33^{* *}$ & $.30^{* *}$ & $.58^{* *}$ & $.48^{* *}$ \\
\hline 10. NDC (P) & .04 & .09 & .01 & .01 & $.81^{\star *}$ & .04 & $.13^{*}$ & $.13^{*}$ & .01 & - & .04 & .09 & $.19^{*}$ & $.54^{\star *}$ & $.57^{* *}$ & $.53^{\star \star}$ \\
\hline 11. EFCDC & $.38^{\star *}$ & $.47^{\star *}$ & $.30^{* *}$ & $.34^{\star *}$ & .05 & $.45^{\star \star}$ & $.43^{\star \star}$ & $.39^{\star *}$ & $.31^{* *}$ & .07 & - & $.61^{\star *}$ & $.61^{\star *}$ & $.46^{* *}$ & $.47^{* *}$ & $.61^{* \star}$ \\
\hline 12. PFCDC & $.31^{* *}$ & $.53^{\star *}$ & $.44^{* *}$ & $.28^{* *}$ & .06 & $.48^{* *}$ & $.49^{* *}$ & $.48^{* *}$ & $.23^{\star *}$ & .11 & $.55^{\star *}$ & - & $.61^{* *}$ & $.55^{\star *}$ & $.54^{* *}$ & $.69^{* *}$ \\
\hline 13. EDC & $.32^{\star \star}$ & $.53^{\star *}$ & $.37^{\star *}$ & $.33^{\star *}$ & .04 & $.41^{\star *}$ & $.52^{\star *}$ & $.42^{* *}$ & $.23^{\star *}$ & $.12^{*}$ & $.42^{\star \star}$ & $.56^{\star \star}$ & - & $.54^{\star *}$ & $.60^{* *}$ & $.66^{\star \star}$ \\
\hline 14. DC (S) & $.57^{\star *}$ & $.65^{\star \star}$ & $.49^{\star *}$ & $.49^{* *}$ & $.67^{\star \star}$ & $.37^{* *}$ & $.38^{* *}$ & $.37^{* *}$ & $.16^{*}$ & $.56^{\star *}$ & $.42^{\star *}$ & $.43^{* *}$ & $.42^{* *}$ & - & $.75^{\star \star}$ & $.92^{* \star}$ \\
\hline 15. DC (P) & $.43^{* *}$ & $.42^{\star *}$ & $.33^{* *}$ & $.24^{\star *}$ & $.44^{\star *}$ & $.62^{\star *}$ & $.68^{\star *}$ & $.63^{\star *}$ & $.50^{\star *}$ & $.62^{\star *}$ & $.47^{\star *}$ & $.52^{\star *}$ & $.50^{\star \star}$ & $.65^{\star *}$ & - & $.92^{* *}$ \\
\hline 16. Overall DC & $.55^{\star *}$ & $.60^{\star *}$ & $.47^{* *}$ & $.41^{* *}$ & $.54^{\star *}$ & $.58^{* *}$ & $.61^{\star *}$ & $.59^{* *}$ & $.39^{* *}$ & $.59^{\star \star}$ & $.61^{\star *}$ & $.64^{\star *}$ & $.55^{\star *}$ & $.87^{* *}$ & $.91^{* *}$ & - \\
\hline
\end{tabular}

Note. Correlation coefficients above the diagonal (above the - symbol) pertain to men and correlation coefficients below the diagonal (below the - symbol) pertain to women. SC = stress communication; EFSDC = emotion focused supportive dyadic coping; PFSDC = problem focused supportive dyadic coping; DDC = delegated dyadic coping; NDC = negative dyadic coping; EDC = evaluation dyadic coping; $\mathrm{DC}=$ dyadic coping; $\mathrm{S}=$ self, $\mathrm{P}=$ partner.

${ }^{*} p<.01 .{ }^{* *} p<.001$.

\section{Confirmatory Factor Analysis (CFA)}

The factor structure of DC by self ( 5 factors), DC by partner ( 5 factors), and common $D C$ ( 2 factors) were tested across gender with a CFA using Amos 23 software (Arbuckle, 2014). The model's fit to the data was evaluated through the common SEM indices including the comparative fit index (CFI > .95), the root mean square error of approximation (RMSEA $<.06$ ), the standardized root mean square residual (SRMR $<.08$ ), non-significant chi-square value $\left(X^{2}\right)$, or $X^{2} / d f \leq 2.0$ test of exact fit (Hu \& Bentler, 1998; Kline, 2013b; Schermelleh-Engel, Moosbrugger, \& Müller, 2003). The fit indices have been reported in Table 4. 
Table 4

CFA Showing Goodness of Fit Indices for DC by Self, DC by Partner and Common DC

\begin{tabular}{|c|c|c|c|c|c|c|}
\hline Model/Factors and item & $\mathrm{x}^{2} / d f$ & GFI & CFI & SRMR & RMSEA & $90 \% \mathrm{Cl}$ \\
\hline \multicolumn{7}{|c|}{ Dyadic coping by self and partner } \\
\hline \multicolumn{7}{|l|}{ Model I } \\
\hline Self ( 5 factors, 15 items $)$ & 1.49 & .94 & .96 & .04 & .03 & {$[.02, .03]$} \\
\hline Partner (5 factors, 15 items) & 1.83 & .93 & .92 & .04 & .03 & {$[.03, .04]$} \\
\hline \multicolumn{7}{|l|}{ Model II } \\
\hline Self ( 5 factors, 13 items $)$ & 1.36 & .96 & .98 & .03 & .02 & {$[.01, .03]$} \\
\hline Partner (5 factors, 13 items) & 1.46 & .96 & .97 & .04 & .03 & {$[.01, .03]$} \\
\hline \multicolumn{7}{|l|}{ Common dyadic coping } \\
\hline \multicolumn{7}{|l|}{ Model III } \\
\hline (2 factors, 5 items) & 1.33 & .99 & .99 & .01 & .02 & {$[.00, .06]$} \\
\hline
\end{tabular}

Note. GFI = goodness of fit index; CFI = comparative fit index; SRMR = standardized root mean square residual;

RMSEA = root mean square error of approximation.

\section{Model 1}

In the Model 1, we examined the factor structure of the DCI used in prior validation studies (e.g., Falconier et al., 2013; Randall et al., 2016; Vedes et al., 2013). As shown in Table 3, the factor structure of DCl-English comprised five factors for DC by self (15 items), same five factor for DC by partner (15 items) and two factors of common DC (5 items; Randall et al., 2016). Upon examining the factor loadings on the items of DC by self i.e., Item 2 "I ask my partner to do things for me when I have too much to do" $\left(\lambda_{\text {men }}=.25, \lambda_{\text {women }}=.22\right)$, Item 3 "I show my partner through my behavior when I am not doing well or when I have problems" $\left(\lambda_{\text {men }}=.30, \lambda_{\text {women }}\right.$ $=.41$ ), and DC by partner Item 17 "My partner asks me to do things for him/her when he has too much to do" $\left(\lambda_{\text {men }}=.32, \lambda_{\text {women }}=.22\right)$ and Item 18 "My partner shows me through his/her behavior that he/she is not doing well or when he/she has problems" $\left(\lambda_{\text {men }}=.20, \lambda_{\text {women }}=.20\right)$ were found to have lowest factor loadings.

\section{Model 2}

In Model 2, model fit indices were re-examined for five factor DC by self (13 items) and five factor DC by partner (13 items). Upon examination, Item 2 "I ask my partner to do things for me when I have too much to do" $\left(\lambda_{\text {men }}=.25, \lambda_{\text {women }}=.22\right)$ and Item 3 "I show my partner through my behavior when I am not doing well or when I have problems" $\left(\lambda_{\text {men }}=.30, \lambda_{\text {women }}=.41\right.$ ), which reflect stress communication by self, and Item 17 "My partner asks me to do things for him/her when he has too much to do" $\left(\lambda_{\text {men }}=.32, \lambda_{\text {women }}=.22\right)$ and Item 18 "My partner shows me through his/her behavior that he/she is not doing well or when he/she has problems" $\left(\lambda_{\text {men }}=.20, \lambda_{\text {women }}=.20\right)$, which reflect stress communication by partner, were found to have the lowest factor loadings. As such, these items were removed.

After removing these items (Item 2, 3, 17, and 18), model fit indices for DC by self were within acceptable range compared to the Model $1\left(\mathrm{GFI}_{\text {model } 1 / \text { model } 2}=.94 / .96, \mathrm{CFI}_{\text {model } 1 / \text { model } 2}=.96 / .98, \mathrm{SRMR}_{\text {model }} 1 / \mathrm{model} 2=.04 / .03\right.$, RMSEA $_{\text {model } 1 / \text { model } 2}=.03 / .02$ ). Similarly, model fit indices for DC by partner indicated acceptable model fit as $\left(\mathrm{GFI}_{\text {model } 1 / \text { model } 2}=.93 / .96, \mathrm{CFI}_{\text {model }} 1 /\right.$ model $2=.92 / .97, \mathrm{SRMR}_{\text {model }} 1 /$ model $2=.04 / .04, \mathrm{RMSEA}_{\text {model }} 1 /$ model 2 $=.03 / .03)$. 


\section{Model 3}

In order to assess factor structure of common DC scale, a separate CFA was carried out. In Model 3, five items $(31,32,33,34,35)$ of common DC were separately tested across the gender. Based on the recommendation of the English version of DCl (Randall et al. 2016), we excluded two items of the evaluation scale i.e., "I am satisfied with the support I receive from my partner and the way we deal with stress together" and "I am satisfied with the support I receive from my partner and I find as a couple, the way we deal with stress together is effective". The model fit indices were found within acceptable range $x^{2} / d f$ (1.33), GFI (.99), CFI (.99), SRMR (.01), and RMSEA (.02) demonstrating that data support the factor structure of common DC scale as proposed by previous validation studies of $\mathrm{DCl}$.

Overall, the factor structure of DCl-Urdu was consistent with that of English version of the DCl (Randall et al., 2016) as shown in Figure 1, except item 9 of emotion-focused supportive DC by partner "My partner listens to me and gives me the opportunity to communicate what really bothers me" and item 24 of emotion-focused supportive DC by self "I listen to my partner and give him/her space and time to communicate what really bothers him/her", retained by the $\mathrm{DCl}-$ Urdu but English version of $\mathrm{DCl}$ did not.

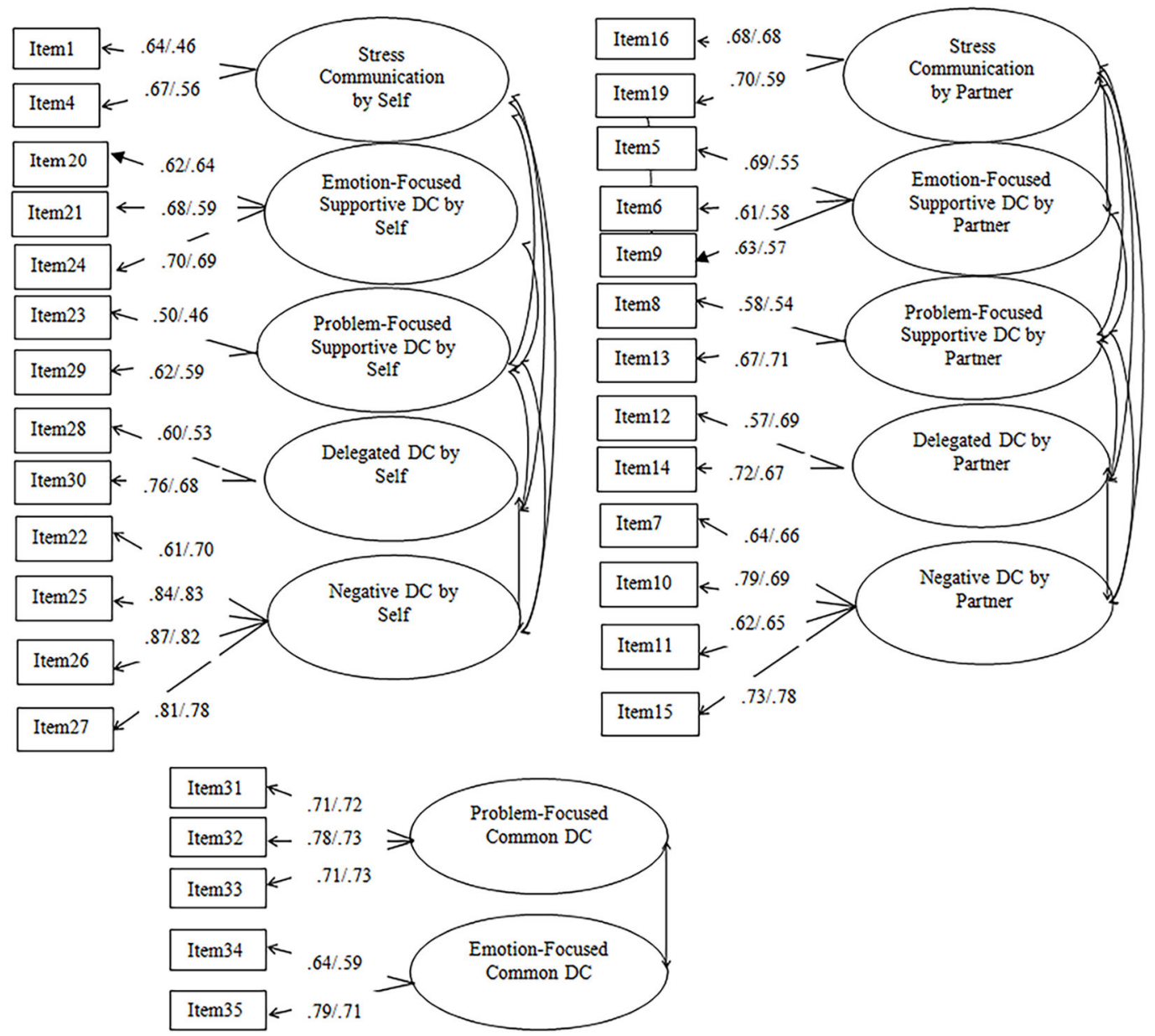

Figure 1. Confirmatory factor analysis of the DCI-Urdu.

Note. Factor loadings on items of five self-related, five partner-related, and two common factors of DCl (Urdu) are significant at $p<.001$. Factor loadings in the numerator pertain to men whereas those in the denominator pertain to women. DC = dyadic coping. 


\section{Construct Validity}

Table 5 provides strong evidence for convergent validity of the $\mathrm{DCl}$-Urdu as overall DC and its subscales were found to be more correlated with relationship satisfaction than use of emotional support and humor. Results revealed that overall DC and its subscales were significantly correlated with relationship satisfaction $(-.34<r$ $>$.73) whereas total DC and its subscales were less correlated with use of emotional support $(-.09<r>.17)$ and humor $(-.05<r>.13)$ indicated discriminant validity of the $\mathrm{DCl}-$ Urdu.

Table 5

Correlation Coefficients Indicating Discriminant and Convergent Validity of the DCI

\begin{tabular}{|c|c|c|c|}
\hline \multirow[b]{2}{*}{ Variable } & \multirow{2}{*}{$\frac{\text { RAS }}{\text { Relationship satisfaction }}$} & \multicolumn{2}{|c|}{ The Brief COPE } \\
\hline & & Use of emotional support & Humor \\
\hline \multicolumn{4}{|l|}{ Self } \\
\hline Stress Communication & $.51^{\star *}$ & .09 & -.19 \\
\hline Emotion Focused Supportive DC & $.68^{\star *}$ & .12 & -.05 \\
\hline Problem Focused Supportive DC & $.36^{*}$ & .24 & -.08 \\
\hline Delegated DC & $.45^{\star}$ & .17 & -.04 \\
\hline Negative DC & $-.34^{*}$ & -.05 & -.19 \\
\hline \multicolumn{4}{|l|}{ Partner } \\
\hline Stress Communication & $.65^{\star *}$ & .10 & -.03 \\
\hline Emotion Focused Supportive DC & $.30^{*}$ & -.02 & -.24 \\
\hline Problem Focused Supportive DC & $.45^{*}$ & .09 & -.19 \\
\hline Delegated DC & $.30^{*}$ & -.17 & -.24 \\
\hline Negative DC & $-.37^{*}$ & .01 & -.08 \\
\hline Emotion Focused Common DC & $.72^{* *}$ & .11 & -.07 \\
\hline Problem Focused Common DC & $.52^{* *}$ & -.04 & .13 \\
\hline Evaluation DC & $.62^{* *}$ & -.01 & .05 \\
\hline Total DC & $.73^{\star *}$ & .09 & -.14 \\
\hline
\end{tabular}

Note. DC = dyadic coping; RAS = Relationship Assessment Scale.

${ }^{*} p<.01 .{ }^{* *} p<.001$.

\section{Measurement Invariance Across Gender}

To assess variance on factor structure of $\mathrm{DCl}-$ Urdu between men and women, configural invariance, metric invariance, and scalar invariance were examined (see Table 6). The configural invariance test established a baseline model and confirmed the similarity of the conceptual framework across the two genders (Chen, 2007). The metric invariance of a scale established the evidence that the two groups had similar responses on the indicators of the scale (Chen, 2007). Scalar invariance was the most stringent invariance test and indicated that the measurement model had the same scale across both the genders (Chen, 2007). A scalarly invariant scale suggested that individuals having the same score on the latent construct would obtain the same score on the observed variable regardless of their gender. 
Table 6

Invariance Tests for DCl Across Gender

\begin{tabular}{|c|c|c|c|c|c|c|c|c|c|}
\hline Invariance level & $x^{2}$ & $d f$ & CFI & RMSEA & Model comparison & $\Delta \mathrm{x}^{2}$ & $\Delta d f$ & $\Delta \mathrm{CFI}$ & $\triangle$ RMSEA \\
\hline \multicolumn{10}{|c|}{ 5-Factor structure DC by self } \\
\hline 1. Configural Invariance & 241.90 & 162 & .96 & .03 & & & & & \\
\hline 2. Metric invariance & 249.47 & 172 & .96 & .02 & 2 vs. 1 & 7.57 & 10 & .001 & .001 \\
\hline 3. Scalar invariance & 274.24 & 187 & .95 & .03 & 3 vs. 1 & 32.3 & 25 & .004 & .000 \\
\hline \multicolumn{10}{|c|}{ 5-Factor structure DC by partner } \\
\hline 1. Configural invariance & 234.20 & 152 & .95 & .03 & & & & & \\
\hline 2. Metric invariance & 240.88 & 162 & .95 & .03 & 2 vs. 1 & 6.68 & 10 & .002 & .002 \\
\hline 3. Scalar invariance & 259.97 & 177 & .95 & .03 & 3 vs. 1 & 25.7 & 25 & .002 & .002 \\
\hline \multicolumn{10}{|c|}{ 2-Factor structure common DC } \\
\hline 1. Configural invariance & 10.66 & 8 & .99 & .01 & & & & & \\
\hline 2. Metric invariance & 11.55 & 11 & .99 & .01 & 2 vs. 1 & 0.89 & 3 & .002 & .003 \\
\hline 3. Scalar invariance & 13.40 & 16 & 1.00 & .00 & 3 vs. 1 & 2.74 & 8 & .003 & .013 \\
\hline
\end{tabular}

Note. RMSEA = root mean square error of approximation; DC = dyadic coping; CFI = goodness of fit index.

For the configural invariance test of the DCl-Urdu, we kept the factor structure of the scale the same across both genders by having the same factor with the same indicators for both genders and freely estimated factor loadings, residuals, and intercepts across the two groups. Results revealed that for all three models (i.e., DC by self, DC by partner, and common DC) the data fit both genders well, which supported the DCl was configural invariant across genders. We constrained the factor loading of the indicators of the DCI-Urdu to be equal across gender for assessing the metric invariance. Findings indicated that the data again fit the model well, which suggests the DCl-Urdu showed metric invariance. Moreover, the comparison of metrically and configuraly invariant models revealed non-significant chi square difference tests and no differences in other measures of fit indices. Finally, for the assessment of the scalar invariance, we constrained the intercepts and the factor loadings to be equal across gender. This scalar invariant model also demonstrated excellent fit to the data. Moreover, the comparison of scalarly invariant models with the configuraly invariant models suggested non-significant chi square difference tests with no differences in CFI and RMSEA values. This demonstrated full scalar invariance of DCI-Urdu across both genders and revealed that both scalarly the configuraly invariant models fit the data equally well. All changes in the CFI and RMSEA for the scalar invariant models were below the critical value of chi square, indicating full scalar invariance across gender for all the three models (Chen, 2007).

\section{Discussion}

The goal of the present study was to assess the psychometric properties of the DCI-Urdu. Consistent with other validation studies of the DCl (Fallahchai et al., 2019; Ledermann et al., 2010; Randall et al., 2016; Rusu et al., 2016; Vedes et al., 2013; Wendołowska, et al., 2020; Xu et al., 2016; Yokotani \& Kurosawa, 2015), all reliability estimates for $\mathrm{DCl}-$ Urdu appeared to be high except few inconsistencies; specifically, stress communication by self $\left(\alpha_{\text {women }}=.41\right)$, problem-focused supportive DC by self $\left(\alpha_{\text {men }}=.50\right.$ and $\left.\alpha_{\text {women }}=.43\right)$, and delegated DC by self $\left(\alpha_{\text {women }}=.53\right)$. These results may be attributed to cultural variations in Pakistan, which is a patriarchal society where women may perceive their partners as less likely to communicate stress experiences with them, 
show practical advice or support, and take over the responsibilities in the time of stress (Qadir et al., 2013). Factor structure of the $\mathrm{DCl}$ was consistent with the that reported by previous validation studies of the $\mathrm{DCl}$ (Bodenmann, 2008; Falconier et al., 2013; Ledermann et al., 2010; Randall et al., 2016; Rusu et al., 2016; Vedes et al., 2013).

Following the factor structure of the DCl-Urdu, construct validity was examined by comparing the DCl-Urdu with relationship satisfaction (Shahid, 2014) and individual coping strategies (Akhtar, 2005). The significant correlation between DCl-Urdu and RAS indicated a positive association between both variables, which is in line with previous validation studies of DCI (e.g., Bodenmann, Pihet, \& Kayser, 2006; Bodenmann \& Randall, 2012; Falconier et al., 2013; Ledermann et al., 2010; Levesque, Lafontaine, Caron, \& Fitzpatrick, 2014). Result from this study suggest that the $\mathrm{DCl}$ shows high predictive power validity for relationship satisfaction for those in Pakistan, contrarily, weak and non-significant correlations between DCl-Urdu and subscales of Brief COPE (Akhtar, 2005) revealed expected differences between individual and dyadic coping as reported previously, illustrating that also in Pakistan culture both coping strategies differ from each other (Bodenmann, 2005; Herzberg, 2013; Papp \& Witt, 2010).

Lastly, results from the tests of measurement invariance demonstrated that the scalar and configural invariant models fit to the data equally well. These results were consistent with the measurement invariance evidence established in U.S. and Swiss samples as reported by Randall et al. (2016).

\section{Limitations and Future Directions}

Data from this study were cross-sectional, which limits the test-retest reliability and predictive validity of the $\mathrm{DCl}$-Urdu. For this purpose, future research should include longitudinal data so that changes in partners' use of DC strategies across various time points may be investigated. Additionally, as independent data from married partners were collected. Future research may include dyadic data so that the interdependence of couples' DC strategies can be analyzed (see lida, Seidman, \& Shrout, 2018). Further, gender role could be an important stressor within couples' relationship in Pakistan that needs to be considered as interpersonal researchers in Pakistan reported strong association between gender role orientation and martial conflict (Sarwar \& Aftab, 2011).

Future research utilizing the $\mathrm{DCl}-$ Urdu is encouraged to take cultural consideration into account. In particular, it would be helpful to include demographically diverse samples from Pakistani culture or foreign cultures in order to enhance the external validity of the study. The socioeconomic status of the couples, the couple's educational levels, and the marriage type (couples married through arranged marriages within the same caste or different caste, couples married through love marriages, and couples married through exchange marriage system) could be relevant demographic variables that should be investigated in the future research. For example, a study in Pakistan reported that marriages arranged by parents without consent of children lack love and such couples are more likely to engage in problem-focused DC compared to the emotion-focused DC (lqbal \& Safdar, 2014).

\section{Conclusions and Implications}

The current study demonstrates that DCl-Urdu is a valid and reliable 33-items self-report measure for assessing stress communication and dyadic coping behaviors for Pakistani married adults. This study opens a new horizon for relationships researchers and family counselors to address stress and coping in Pakistan. The 
DCl-Urdu has the potential to help family counselors understand the dyadic nature of stress and coping strategies in Pakistan. This study would direct the clinicians and counselors to devise STM based interventions or to adapt Couples Coping Enhancement Training (CCET) program to prevent couples from marital distress and to promote coping skills to overcome dyadic stress (Bodenmann \& Shantinath, 2004).

\section{Funding}

The authors have no funding to report.

\section{Competing Interests}

The authors have declared that no competing interests exist.

\section{Acknowledgments}

The authors would like to thank the participants for participating in this study.

\section{References}

Acquadro, C., Conway, K., Giroudet, C., \& Mear, I. (2012). Linguistic validation manual for health outcome assessments. Mapi Institute. Retrieved from https://www.scienceopen.com /document?vid=510be620-8542-417b-955f-d8937019be74

Akhtar, M. (2005). Coping strategies and its relationship with stress and time demands among university students [Unpublished thesis]. National Institute of Psychology, Quaid-e-Azam University, Islamabad, Pakistan.

Ali, T. M., \& Gul, S. (2018). Community mental health services in Pakistan: Review study from Muslim world 2000-2015. Psychology, Community \& Health, 7(1), 57-71. https://doi.org/10.5964/pch.v7i1.224

Ali, T. S., Krantz, G., Gul, R., Asad, N., Johansson, E., \& Mogren, I. (2011). Gender roles and their influence on life prospects for women in urban Karachi, Pakistan: A qualitative study. Global Health Action, 4(1), Article 7448. https://doi.org/10.3402/gha.v4i0.7448

Arbuckle, J. L. (2014). IBM SPSS Amos 23.0 User's guide. Retrieved from http://amosdevelopment.com/

Arif, N., \& Fatima, I. (2015). Marital satisfaction in different types of marriage. Pakistan Journal of Social and Clinical Psychology, 13(1), 36-40.

Arshad, Z., \& Iqbal, N. (2016). Dyadic coping in Pakistani couples. In M. K. Falconier, A. K. Randall, \& G. Bodenmann (Eds.), Couples coping with stress: A cross-cultural perspective (pp.203-217). New York, NY, USA: Routledge.

Bakker, A. B., Demerouti, E., \& Burke, R. (2009). Workaholism and relationship quality: A spillover-crossover perspective. Journal of Occupational Health Psychology, 14, 23-33. https://doi.org/10.1037/a0013290

Bodenmann, G. (1995). A systemic-transactional conceptualization of stress and coping in couples. Swiss Journal of Psychology, 54(1), 34-49.

Bodenmann, G. (1997). Dyadic coping: A systematic-transactional view of stress and coping among couples: Theory and empirical findings. European Review of Applied Psychology, 47(2), 137-140. 
Bodenmann, G. (2005). Dyadic coping and its significance for marital functioning. In T. Revenson, K. Kayser, \& G. Bodenmann (Eds.), Couples coping with stress: Emerging perspectives on dyadic coping (pp. 33-50). Washington, DC, USA: American Psychological Association. https://doi.org/10.1037/11031-002

Bodenmann, G. (2007). Dyadic coping and the 3-phase-method in working with couples. In L. VandeCreek (Ed.), Innovations in clinical practice: Focus on group and family therapy (pp. 235-252). Sarasota, FL, USA: Professional Resources Press.

Bodenmann, G. (2008). Dyadisches coping inventar: Testmanual [Dyadic Coping Inventory: Test manual]. Bern, Switzerland: Huber.

Bodenmann, G., \& Randall, A. K. (2012). Common factors in the enhancement of dyadic coping. Behavior Therapy, 43, 88-98. https://doi.org/10.1016/j.beth.2011.04.003

Bodenmann, G., \& Shantinath, S. D. (2004). The Couples Coping Enhancement Training (CCET): A new approach to prevention of marital distress based upon stress and coping. Family Relations, 53(5), 477-484.

https://doi.org/10.1111/j.0197-6664.2004.00056.x

Bodenmann, G., Pihet, S., \& Kayser, K. (2006). The relationship between dyadic coping and marital quality: A 2-year longitudinal study. Journal of Family Psychology, 20(3), 485-493. https://doi.org/10.1037/0893-3200.20.3.485

Carver, C. S. (1997). You want to measure coping but your protocol'too long: Consider the brief cope. International Journal of Behavioral Medicine, 4(1), 92-100. https://doi.org/10.1207/s15327558ijbm0401_6

Chen, F. F. (2007). Sensitivity of goodness of fit indexes to lack of measurement invariance. Structural Equation Modeling, 14(3), 464-504. https://doi.org/10.1080/10705510701301834

Coyne, J. C., \& Smith, D. A. (1991). Couples coping with a myocardial infarction: A contextual perspective on wives' distress. Journal of Personality and Social Psychology, 61(3), 404-412. https://doi.org/10.1037/0022-3514.61.3.404

DeLongis, A., \& O'Brien, T. (1990). An interpersonal framework for stress and coping: An application to the families of Alzheimer's patients. In M. A. P. Stephens, J. H. Crowther, S. E. Hobfoll, \& D. L. Tennenbaum (Eds.), Stress and coping in later-life families (pp. 221-239). New York, NY, USA: Hemisphere Publishing Corp.

Falconier, M. K., Jackson, J., Hilpert, J., \& Bodenmann, G. (2015). Dyadic coping and relationship satisfaction: A metaanalysis. Clinical Psychology Review, 42, 28-46. https://doi.org/10.1016/j.cpr.2015.07.002

Falconier, M. K., Nussbeck, F., \& Bodenmann, G. (2013). Immigration stress and relationship satisfaction in Latino couples: The role of dyadic coping. Journal of Social and Clinical Psychology, 32(8), 813-843.

https://doi.org/10.1521/jscp.2013.32.8.813

Falconier, M., Randall, A., \& Bodenmann, G. (2016). Couples coping with stress: A cross- cultural perspective. New York, NY, USA: Routledge. https://doi.org/10.4324/9781315644394

Fallahchai, R., Fallahi, M., Chahartangi, S., \& Bodenmann, G. (2019). Psychometric properties and factorial validity of the dyadic coping inventory-the Persian version. Current Psychology, 38(2), 486-496.

https://doi.org/10.1007/s12144-017-9624-6 
Fatima, M., \& Ajmal, M. A. (2012). Happy marriage: A qualitative study. Pakistan Journal of Social and Clinical Psychology, $9(2), 37-42$.

Gallup Pakistan. (2019). Gallup Pakistan survey. Retrieved from https://gallup.com.pk/post/29751

Hendrick, S. S., Dicke, A., \& Hendrick, C. (1998). The relationship assessment scale. Journal of Social and Personal Relationships, 15(1), 137-142. https://doi.org/10.1177/0265407598151009

Herzberg, P. Y. (2013). Coping in relationships: The interplay between individual and dyadic coping and their effects on relationship satisfaction. Anxiety, Stress, and Coping, 26(2), 136-153. https://doi.org/10.1080/10615806.2012.655726

Hilpert, P., Randall, A. K., Sorokowski, P., Atkins, D. C., Sorokowska, A., Ahmadi, K., . . Błażejewska, M. (2016). The associations of dyadic coping and relationship satisfaction vary between and within nations: A 35-nation study. Frontiers in Psychology, 7, Article 1106. https://doi.org/10.3389/fpsyg.2016.01106

Hu, L. T., \& Bentler, P. M. (1998). Fit indices in covariance structure modeling: Sensitivity to underparameterized model misspecification. Psychological Methods, 3(4), 424-453. https://doi.org/10.1037/1082-989X.3.4.424

lida, M., Seidman, G., \& Shrout, P. E. (2018). Models of interdependent individuals versus dyadic processes in relationship research. Journal of Social and Personal Relationships, 35(1), 59-88. https://doi.org/10.1177/0265407517725407

Iqbal, N., \& Safdar, H. (2014). Emotional stability, intimacy and dyadic coping and its relationship with marital satisfaction among love and arranged married couples [Unpublished master's thesis]. International Islamic University, Islamabad, Pakistan.

Khalil, R., Naeem, Z., Yousafzai, M. T., \& Gul, S. (2014). Marriage as a bond or a burden: A study on married female college teachers of Karachi, Pakistan. International Journal of Social Sciences and Education, 4(3), 636-642.

Kline, R. B. (2013b). Exploratory and confirmatory factor analysis. In Y. Petscher \& C. Schatsschneider (Eds.), Applied quantitative analysis in the social sciences (pp. 171-207). New York, NY, USA: Routledge.

Ledermann, T., Bodenmann, G., Rudaz, M., \& Bradbury, T. N. (2010). Stress, communication, and marital quality in couples. Family Relations, 59(2), 195-206. https://doi.org/10.1111/j.1741-3729.2010.00595.x

Lentz, T. F. (1938). Acquiescence as a factor in the measurement of personality. Psychological Bulletin, 35(9), 659.

Levesque, C., Lafontaine, M. F., Caron, A., \& Fitzpatrick, J. (2014). Validation of the English version of the Dyadic Coping Inventory. Measurement \& Evaluation in Counseling \& Development, 47(3), 215-225.

https://doi.org/10.1177/0748175614522272

Mir, M. S., Wani, M. A., \& Sankar, R. (2016). Marital adjustment among love marriage and arranged marriage couples. The International Journal of Indian Psychology, 3(3), 51-56. https://doi.org/10.25215/0303.065

Mujtaba, B. G., Lara, A., King, C., Johnson, V., \& Mahanna, T. (2010). Stress at work in a slowing economy. The Journal of Applied Management and Entrepreneurship, 15(2), 26-42.

Niaz, U. (2004). Women's mental health in Pakistan. World Psychiatry, 3(1), 60-62. Retrieved from https://www.ncbi.nlm.nih.gov/pmc/articles/PMC1414670 
Papp, L. M., \& Witt, N. L. (2010). Romantic partners' individual coping strategies and dyadic doping: Implications for relationship functioning. Journal of Family Psychology, 24(5), 551-559. https://doi.org/10.1037/a0020836

Qadir, F., Khalid, A., Haqqani, S., Zill-e-Huma, \& Medhin, G. (2013). The association of marital relationship and perceived social support with mental health of women in Pakistan. BMC Public Health, 13(1), Article 1150.

https://doi.org/10.1186/1471-2458-13-1150

Qadir, F., Khan, M. M., Medhin, G., \& Prince, M. (2011). Male gender preference, female gender disadvantage as risk factors for psychological morbidity in Pakistani women of childbearing age-a life course perspective. BMC Public Health, 11(1), Article 745. https://doi.org/10.1186/1471-2458-11-745

Randall, A. K., \& Bodenmann, G. (2009). The role of stress on close relationships and marital satisfaction. Clinical Psychology Review, 29(2), 105-115. https://doi.org/10.1016/j.cpr.2008.10.004

Randall, A. K., Hilpert, P., Jimenez-Arista, L. E., Walsh, K. J., \& Bodenmann, G. (2016). Dyadic coping in the US: Psychometric properties and validity for use of the English version of the Dyadic Coping Inventory. Current Psychology, 35(4), 570-582. https://doi.org/10.1007/s12144-015-9323-0

Revenson, T. A. (1994). Social support and marital coping with chronic illness. Annals of Behavioral Medicine, 16(2), 122-130.

Rusu, P. P., Hilpert, P., Turliuc, M. N., \& Bodenmann, G. (2016). Dyadic coping in an Eastern European context: Validity and measurement invariance of the Romanian version of dyadic coping inventory. Measurement \& Evaluation in Counseling \& Development, 49(4), 274-285. https://doi.org/10.1177/0748175616664009

Saleem, H., Chaudhry, A. G., \& Riaz, M. (2015). Endogamy and marital alliances: Anthropology of indigenous marriage patterns. Science International, 27(2), 1603-1605.

Sarfraz, H. (2017). Let's talk about depression. The Express Tribune. Retrieved from https://tribune.com.pk/story/1376547/lets-talk-depression

Sarwar, A., \& Aftab, H. (2011). Work stress and family imbalance in service sector of Pakistan. International Journal of Business and Social Science, 2(13), 250-261.

Schermelleh-Engel, K., Moosbrugger, H., \& Müller, H. (2003). Evaluating the fit of structural equation models: Tests of significance and descriptive goodness-of-fit measures. Methods of Psychological Research Online, 8(8), 23-74.

Shahid, A. (2014). Psychological predictors of psychological health among pregnant women and their infant's birth weight in Punjab [Unpublished thesis]. University of Sargodha, Pakistan.

UNESCO. (2018). UNESCO Pakistan country strategic document 2018-2022. Retrieved from https://en.unesco.org/sites/default/files/ucsd.pdf

Vedes, A., Nussbeck, F. W., Bodenmann, G., Lind, W., \& Ferreira, A. (2013). Psychometric properties and validity of the Dyadic Coping Inventory in Portuguese. Swiss Journal of Psychology, 72(3), 149-157.

https://doi.org/10.1024/1421-0185/a000108 
Wendołowska, A. M., Czyżowska, D., \& Bodenmann, G. (2020). Psychometric properties and measurement invariance of the Polish version of the dyadic coping inventory. Current Psychology. Advance online publication. https://doi.org/10.1007/s12144-020-00623-5

World Health Organization. (2016). Non-communicable diseases risk factors survey - Pakistan. Retrieved from https://www.who.int/ncds/surveillance/steps/2014_Pakistan_STEPS_Report.pdf

Xu, F., Hilpert, P., Randall, A. K., Li, Q., \& Bodenmann, G. (2016). Validation of the Dyadic Coping Inventory with Chinese couples: Factorial structure, measurement invariance, and construct validity. Psychological Assessment, 28(8), e127e140. https://doi.org/10.1037/pas0000329

Yokotani, K., \& Kurosawa, T. (2015). A pilot examination of Dyadic Coping Inventory among Japanese married couples. Psychologia, 58(3), 155-164. https://doi.org/10.2117/psysoc.2015.155

Zafar, N., \& Kausar, R. (2014). Emotional and social problems in divorced and married women. FWU Journal of Social Sciences, 8(1), 31-35. Retrieved from

http://sbbwu.edu.pk/journal/

FWU_Journal_Summer2014,Vol.8,No.1/5_Emotional_and_Social_Problems_in_Divorced.pdf

Zaman, M. (2011a). Exchange marriages in South Punjab, Pakistan. Frankfurt, Germany: Peter Lang Publishing.

Zaman, N. I., \& Ali, U. (2014). Predictive role of problem focused coping in the psychological well being of university students. Journal of Pakistan Psychiatric Society, 11(2), 23-27. 